\title{
ERNESTO SABATO: OJOS PARA LO SAGRADO
}

\author{
POR \\ LUIS MONTIEL \\ Universidad Complutense, Madrid (España)
}

Literatura, ONTOFANíA, hiERofaníA

Ernesto Sábato se ha preguntado en diversas ocasiones por qué se escriben ficciones ${ }^{1}$. Parece justo que quien escribe ensayos, conatos de interpretación de estas mismas ficciones, se pregunte igualmente por qué lo hace. ¿Pretende, tal vez, saber más sobre una obra que el propio autor? ¿Considera que tal obra es un críptico mensaje para iniciados, que éstos, a su vez, tienen que explicar a los neófitos? No lo creo; al menos, no es así en el caso presente. Pienso más bien que pertenece a la esencia de la obra de ficción una inagotable capacidad de sugerencia, incluso de provocación. Así lo entiende Michel Foucatilt en relación con la literatura ulterior a Nietzsche y a Mallarmé ${ }^{2}$, de manera que, cuando se lee una obra como la de Sábato, restlta imposible mantenerse al margen. Todo en ella nos concierne porque todo en ella nos habla, aunque con un lenguaje grávido, que debe desdoblarse, ante el que sólo cabe ejercer de partero si se quiere llegar al final. Escriba o no al respecto, todo lector de Sábato $-\mathrm{y}$ de tantos otros autores del presente siglo- debe convertirse en intérprete o no conseguirá nada. Se atribuye a Eugenio d'Ors - no conozco exactamente la procedencia de la cita-

1 Lo ha hecho en sus ensayos, principalmente en El escritor y sus fantasmas (1963), publicado en Ensayos (Buenos Aires: Losada, 1970), pp. 457-802, pero también en su novela Abaddón el exterminador (Barcelona: Seix Barral), pp. 169-185.

2 Esta tesis está desarrollada pormenorizadamente en la segunda parte de Las palabras y las cosas (México: Siglo XXI, 1982). Formulada de manera compendiosa, se encuentra también en "La locura, la ausencia de obra», apéndice a la edición castellana de Historia de la locura en la época clásica (México: Fondo de Cultura Económica, 1967), pp. 336-340. 
la clasificación de los escritores en dos grandes grupos: los que dicen una cosa detrás de otra y los que dicen una cosa dentro de otra. El primero de estos lenguajes es, sin duda, indispensable para la ciencia; en cuanto al segundo, el propio Sábato ha dejado claro en sus ensayos hasta qué punto considera que es el único posible para ese modo de conocer la realidad que es el arte.

El presente trabajo se sitúa en un espacio liminar a ambos campos; pues, a priori, hay que suponer que pretende ser científico, pero, por otra parte, hoy resulta complicado definir los criterios de cientificidad en el análisis de la literatura. El citado Foucault, al problematizar como lo ha hecho el uso del lenguaje, obliga al crítico a ser, a partir de ahora, excepcionalmente cuidadoso. Un lenguaje que explique la obra de arte corre el riesgo de traicionar su auténtico significado. Quizá sólo sea lícito aceptar el reto de la ambiguiedad y retomar, desde dentro - desde su propia ley-, el mensaje interminable.

Lo primero que necesitamos saber es qué piensa Sábato que hace cuando escribe ficciones. $\mathrm{Y}$ en esto el autor es terminante:

Es evidente que el arte es un lenguaje más emparentado con el sueño y con el mito que con las estadísticas y las crónicas de los periódicos. Como el sueño y el mito es una ontofanía (...), una revelación de la realidad. Pero de toda la realidad, jeh! De toda. No sólo de la exterior, sino de la interior. No sólo de la racional, sino de la irracional ${ }^{3}$.

La literatura, o al menos la que Sábato quiere hacer, es una ontofanía como el mito. Pero, además de ontofanía, el mito es hierofanía, manifestación de lo sagrado. No en vano Zubiri explica el sentimiento religioso como conciencia de la religación con la realidad ${ }^{4}$, sacralizando así lo real, en una línea que, cuando menos, procede de un pensador tan caro a Sábato como es Karl Jaspers. Por otra parte, el lenguaje mítico y el literario aparecen en la citada frase vinculados al lenguaje onírico, y la realidad desdoblada en un nivel exterior y otro interior. E1 intérprete sólo podrá alcanzar su objetivo si toma este hilo conductor que le ofrece - como ya ocurriera in illo tempore - el constructor de su propio laberinto; si es capaz de reconocer que el cordel y el laberinto no son dos cosas diferentes.

3 Abaddón el exterminador, pp. 179-180.

${ }^{4}$ Sobre el significado del concepto de religación en Zubiri, véase D. Gracia, Voluntad de verdad. Para leer a Zubiri (Barcelona: Labor, 1986), pp. 211-236. 


\section{LA CONCIENCIA, EL LABERINTO, EL MINOTAURO}

No es casual que el único de los personajes sabatianos a quien su autor califica de héroe, Fernando Vidal Olmos ${ }^{5}$, adquiera conciencia de su papel en el interior de un laberinto, que empieza en las alcantarillas de Buenos Aires para perderse luego en una profundidad fuera del tiempo y del espacio de los hombres; una profundidad que tiene que ser tan vasta para dar cuenta de lo insondable que es el propio interior, a poco que uno se arriesgue a escrutarlo: para llegar a ser auténticamente humana tiene que empezar por parecernos inhumana en grado sumo. No es, digo, casual, por cuanto ya Nietzsche se vio obligado a utilizar la metáfora del laberinto para explicar cómo, quien desee encontrarse, tiene antes que perderse, hasta arriesgar la perdición definitiva:

Ser independiente es cosa de una pequeña minoría, es el privilegio de los fuertes. El que trata de serlo, aun con derecho a ello, pero sin estar obligado a ello, prueba por lo mismo que no es solamente fuerte, sino también audaz en grado temerario. Se aventura en un laberinto, multiplica hasta el infinito los peligros que la vida trae ya consigo. $\mathrm{Y}$ el menor de estos peligros no es que nadie vea con sus propios ojos cómo se extravía, desgarrado en la soledad por algún subterráneo minotauro de la conciencia. Suponiendo que tal hombre pereciese, sería tan lejos del conocimiento de los hombres que éstos no podrían ni sentirle ni comprenderle. iY no está en su poder volver atrás! ¡No puede tampoco volver a la compasión de los hombres! ${ }^{6}$

Como queda dicho, la parte final -y definitiva- del «Informe sobre ciegos» transcurre en un laberinto subterráneo, que es primero el de las cloacas de Buenos Aires y luego el laberinto utópico y ucrónico -en el sentido literal, es decir, fuerte, de estos términos- de la existencia de su autor en la ficción, Fernando Vidal Olmos. Utópico y ucrónico, digo, porque lo que allí ocurre está fuera del tiempo y del espacio, en esa región difusa del sueño en la que nada tiene que ver la situación en que se encuentra el cuerpo del durmiente ni el momento en que sueña, y la misma reviviscencia de hechos, lugares y momentos pretéritos está sometida a unas reglas que no son las del acontecer diurno. Nos encontramos en lo profundo, en lo que presentimos - también en

5 «De pronto me sentí una especie de héroe, de héroe al revés, héroe negro y repugnante, pero héroe» (Sobre héroes y tumbas [Barcelona, Seix Barral, 1978], p. 425).

6. Nietzsche, F., «Jenseits von Gut und Böse», en Werke, vol. II (Ed. K. Schlechta) (München: Hanser, 1955), pp. 594-595. 
sentido literal - fundamental o fundamentante. Resulta, ahora, oportuno traer a colación la enantiosis bachelardiana constituida por la casa y el laberinto, idéntica a la establecida por Sábato en su obra de ficción; señala Bachelard la existencia de tres grandes imágenes del refugio: la casa, el vientre (siempre materno) y la gruta. Pero el último de los componentes de esta tríada introduce un factor perturbador del cálido ambiente imaginario: a partir de la imagen de la gruta se 1lega, como sin quererlo, a la del laberinto, que no es ya un refugio, sino una incitación, acuciante, al movimiento, pues cambia en inseguridad, en zozobra, en temor, la seguridad ofrecida por las otras metáforas de lo oscuro, cálido y cerrado ${ }^{7}$. No obstante, hay que aclarar que la enantiosis que acabamos de formular tiene precisamente el sentido que, desde Heráclito, caracteriza a este modo de entender la realidad: la ley de la enantiosis es la enantiodromia, la tendencia de cada uno de los polos de la oposición a convertirse en su contrario, a fundirse con él en una forma compleja - pero más real- del ser, que el entendimiento humano sólo puede pensar como continua tendencia o continuo movimiento de un polo al otro. De manera que la casa y el laberinto no deben entenderse como extremos de una línea recta de extensión casi infinita, sino como imágenes que comparten con la situación de la que proceden -el sueñoesa calidad ambigua que tanto cuesta aceptar al intelecto en sus horas de vigilia. El laberinto, lo veremos, es imagen desazonadora, angustiante, pero también prometedora de una paz deseada: la paz que en el castigo busca el criminal; la que en la verdad persigue el mentiroso. La casa, por su parte, es el espacio del recuerdo infantil, de la madre, de los hermanos, de los primeros juegos; pero este recuerdo es el desencadenante de la pesquisa subterránea. Que el recuerdo de la casa, que la casa en sí pueden ser tan angustiosos como el laberinto es algo que se vive desde la primera descripción del mirador de Barracas en Sobre héroes y tumbas. Que la casa es el acceso al laberinto es algo que Sábato tarda más en asumir, pero no escapa a ese cruel autoanálisis que es Abaddón.

Sabemos ya dónde nos encontramos cuando decidimos acompañar a Fernando Vidal en su descenso a los infiernos de su propio conocimiento. Pero, además, necesitamos saber de qué calidad es nuestra nueva instalación. Según el personaje, nos encontramos en «el reverso del mundo» ${ }^{8}$; esto es, en la otra cara de la realidad, pero, en todo caso, en

7 Bachelard, G., La terre et les rêveries de la volonté (París: José Corti, 1973), pp. 14-15.

8 El contexto en que Fernando Vidal Olmos formula esta definición es, en principio, diferente; v. Sobre héroes y tumbas, p. 356. No obstante, en otro lugar 
la realidad. En cuanto al valor de esta otra cara, oigamos la opinión de Bachelard:

Cuando se sabe dar a todas las cosas su justo peso de sueños, habitar oníricamente es más que habitar por el recuerdo?.

Podrá o no compartirse esta valoración; en todo caso es idéntica a la que se obtiene de la lectura de la obra de Sábato. Y habitar oníricamente es lo que harán los personajes sabatianos - y sobre todo Fernando y «Sábato»- cada uno en su casa natal; esa casa arquetípica que hace que

... el mundo real se borre de un sólo golpe (...). ¿Qué valen las casas de la calle cuando se evoca la casa natal, la casa de la intimidad absoluta, la casa donde se ha adquirido el sentido de la intimidad? ${ }^{10}$

Como acabo de advertir, la asociación entre la casa y el laberinto es definitivamente aceptada sólo al final de Abaddón, lo que da cuenta de la extrema dificultad del reconocimiento, así como de la conciencia del peligro en que se pone quien se arriesga a encontrar, en el fondo del refugio de la intimidad, los sospechados corredores subterráneos:

Ahora, después de cuarenta y cinco años, estaba de vuelta en la vieja casa de la calle Arcos (...). Comprendió que ya era hora.

Se incorporó y caminó hacia la mampara de vidrios rotos, derruida por el tiempo y la incuria. Abrió con esfuerzo la puerta oxidada y empezó la marcha hacia los subsuelos, rehaciendo con su linterna el camino de otro tiempo.

Sabía que al término de aquel laberinto algo estaba esperándolo. Pero no sabía qué ${ }^{11}$.

Por lo pronto, responderá Bachelard, el pasado. $\mathrm{Y}$ un pasado que es, a la vez, el pasado del individuo que sueña y un pasado «más lejano, más incierto, ese pasado enorme que ya no tiene fecha, que ya no sabe las fechas de nuestra historia» ${ }^{12}$. No se trata aquí de un pasado que podríamos 1lamar «histórico», del pasado en sentido cronológico -o

he tratado de probar que tal definición es sobre todo aplicable a su pesquisa en el inconsciente: Montiel, L., "Sobre torres y cloacas. La heterodoxia de Ennesto Sábato», en Quirón, vol. XVI, 2/4, 1985, pp. 57-68.

${ }^{9}$ Bachelard, G., La terre et les rêveries du repos (París: José Corti, 1974), p. 98.

\footnotetext{
10 Ibid., p. 95.

11 Pp. 420-421.

12 Bachelard, G. (1974), p. 124.
} 
al menos no sólo de éste-, sino de eso que está «antes» o «debajo» en un sentido genético o tectónico. Porque esto es así, porque la angustia que produce el laberinto procede de la profundidad del inconsciente, es por lo que esta ansiedad es universal, puede ser experimentada por cualquiera ${ }^{13}$. Y lo que esta ansiedad revela es que la intimidad es peligrosa ${ }^{14}$; pero nadie puede renunciar a ella, pues nadie puede existir sin ella:

Debajo de la elevada casa psíquica hay en nosotros un laberinto que conduce a nuestro infierno ${ }^{15}$.

Una vía de todos conocida, a disposición de todos, para acceder a este laberinto es el sueño, "pasajero suburbio de la muerte» ${ }^{16}$. A través de este portillo se accede a los subterráneos meandros del inconsciente,

de modo que al día siguiente somos y no somos los mismos, pues ya pesan sobre nosotros las secretas y abominables experiencias de la noche ${ }^{17}$.

Hamann, el «mago del norte» de los románticos alemanes 1lamó al sueño «Höllenfahrt der Selbsterkenntnis» (viaje al infierno del autoconocimiento) ${ }^{18}$. Con todo, esta indagación, por su carácter involuntario, puede resultar escasamente útil. Es necesario realizar un esfuerzo de la voluntad para descifrar y aceptar los mensajes del mundo onírico. Pero este mismo esfuerzo puede conducir al inicio de investigaciones más conscientes, más peligrosas, como la representada en el viaje subterráneo de Fernando Vidal Olmos. Fernando se guía por una convicción que es, a la vez, un descubrimiento:

No hay casualidades, sino destinos. No se encuentra sino lo que se busca, y se busca lo que en cierto modo está escondido en lo más profundo y oscuro de nuestro corazón ${ }^{19}$.

13 «E1 sueño del laberinto (...) puede suministrar un buen ejemplo de los arquetipos evocados por C. G. Jung. Robert Desoille ha precisado esta noción de arquetipo (...). Un arquetipo es (...) una serie de imágenes que resumen la experiencia ancestral del hombre ante una situación típica, es decir, en circunstancias que no son particulares de un solo individuo, sino que pueden imponerse a cualquiera» [Bachelard, G. (1974), p. 211].

14 Ibid., p. 258.

15 Ibid., p. 232.

16 Sobre héroes y tumbas, p. 156.

17 Ibid.

18 Cit. por Beguin, A., El alma romántica y el sueño (México: Fondo de Cultura Económica, 1981), p. 81.

19 P. 501. 
Al elegir, a todo riesgo, el conocimiento de la verdad, Fernando puede ver, desde el fondo de las cloacas, lo que ocurre en la domesticada superficie, así como lo que bajo esta superficie se oculta:

$\mathrm{Y}$ todo marchaba hacia la Nada del océano mediante conductos subterráneos y secretos, como si Aquellos de Arriba se quisiesen olvidar, como si intentaran hacerse los desentendidos sobre esta parte de su verdad. Y como si héroes al revés, como yo, estuvieran destinados al trabajo infernal y maldito de dar cuenta de esa realidad (...). Sí, de pronto me sentí una especie de héroe, de héroe al revés, héroe negro y repugnante, pero héroe. Una especie de Sigfrido de las tinieblas, avanzando en la oscuridad y la fetidez con mi negro pabellón restallante, agitado por los huracanes infernales ${ }^{20}$.

Al que ha pasado por estos trances -o, más exactamente, al que ha elegido ponerse en este peligro - le resulta imposible abandonar la búsqueda de "esa parte de la verdad»; todo retorno a lo establecido está vedado; y en medio de la oscuridad, el explorador empieza a desarrollar una nueva mirada, se vuelve nictálope de su propia noche.

\section{Ojos del hombre, ojos de Edipo, ojos de Perséfone}

Esta mirada nueva, ganada en el peligro, no representa en modo alguno el reposo, sino, muy al contrario, la perpetuación del riesgo y su despliegue hacia niveles cada vez más amplios. Como era de esperar, la propia noción de sí mismo y del ser humano en general no queda incólume cuando esta mirada reposa sobre ella. Para empezar, quien reconoce la existencia de un arriba y un abajo, de un exterior y un interior, no puede dejar de ser dualista. En repetidas ocasiones las criaturas sabatianas dan cuenta de tal experiencia de su autor; la propia existencia de estas criaturas, polarmente orientadas, es una prueba más de ella. Sin duda la más bella de las frases en que se manifiesta tal creencia es la puesta en boca de Bruno:

E1 alma no puede manifestarse a nuestros ojos materiales sino por medio de la materia, y eso es una precariedad del alma, pero también una curiosa sutileza ${ }^{21}$.

Pero, por otra parte, este dualismo constituye la raíz de la radical escisión -escisión que, como veremos, es la esencia misma de la enfermedad- del ser humano:

20 P. 425.

21 Sobre héroes y tumbas, p. 20. 
El hombre, al levantarse sobre las dos patas traseras y al convertir en un hacha la primera piedra filosa, instituyó las bases de su grandeza, pero también los orígenes de su angustia; porque con sus manos y con los instrumentos hechos con sus manos iba a erigir esa construcción tan potente y extraña que se llama cultura e iba a iniciar así su gran desgarramiento, ya que habrá dejado de ser un simple animal pero no habrá llegado a ser el dios que su espíritu le sugiriera ${ }^{22}$.

Este desgarramiento, esta escisión, es el hecho morboso por antonomasia, de manera que la salud - como, por otra parte, era previsible en este sistema- deja de ser el estado natural del organismo individual para convertirse en una excepción, fruto de una tensión total, dolorosa, mantenida, mediante la cual el individuo intenta seguir siendo, en la medida de lo posible, inl-dividuo. Así, la precaria salud resulta ser sufrimiento, al paso que la enfermedad $-\mathrm{y}$, sobre todo, la más humana de las enfermedades, la locura- puede llegar a ser reposo; perverso si se quiere, pero reposo al fin. Fernando Vidal confiesa en su «Informe» que

... cuando tenía menos de veinte años (...) tuve de pronto la revelación de que la realidad podía empezar a deformarse si no concentraba toda mi voluntad para mantenerla estable (...). La gente no comprendía lo que me pasaba, me veía concentrarme, con mi mirada fija y ajena, y creía que me estaba volviendo loco, sin comprender que era al revés, precisamente al revés, puesto que merced a aquel esfuerzo lograba mantener la realidad en su sitio y en su forma ${ }^{23}$.

Cuando atravesaba estos momentos — que, a la luz de todo lo anterior, hemos de considerar como de lucidez superior- deseaba, nos dice,

... que me encerraran en un manicomio para descansar, puesto que allí nadie tiene la obligación de mantener la realidad como se pretende que es. Como si allí uno pudiera decir (y seguramente dice): ahora, que se arreglen ${ }^{24}$.

El análisis de la transvaloración realizada en la obra de Sábato merecería espacio y tiempo mucho más dilatados. Al menos lo esencial -lo que yo considero esencial - ha quedado señalado en estas breves páginas. Henos, pues, aquí poseedores-poseídos de un nuevo saber, de una mirada nueva. ¿Adónde conduce esta mirada? En el caso de Fer-

\footnotetext{
22 Ibid., p. 521

$23 \mathrm{Pp} .306 \cdot 307$.

24 P. 307.
} 
nando Vidal Olmos, a la aniquilación, a la muerte. En esto coincide su peripecia novelística con la histórica peripecia de Nietzsche, a quien tomaremos, de nuevo, como punto de referencia. Nietzsche, sabio, cae en la locura. Antes de llegar a ella había sido capaz de comprender el riesgo que corría: su lectura del mito de Edipo, sobre la que volverá Karl Jaspers al estudiar el tema de la verdad en Nietzsche ${ }^{25}$, resulta profética:

En esta horrible tríada de los destinos de Edipo reconozco la marca evidente de esta verdad: aquél que resuelve el enigma de la naturaleza - la híbrida esfinge - debe también, como asesino de su padre y esposo de su madre, quebrantar las más altas leyes de la naturaleza. Sí; el mito parece murmurar en nuestro oído que la sabiduría (...) es una abominación contra naturaleza; que aquel que por su saber precipita a la naturaleza en el abismo de la nada debe atenerse también a experimentar por sí mismo los efectos de la disolución de la naturaleza ${ }^{26}$.

El ejercicio de esta nueva mirada repetiría, pues, el acto satánico primordial - la cata del fruto prohibido del árbol de la ciencia-, pero también, en no menor medida, el acto prometeico: existe un fuego que no debe ser sólo patrimonio de los dioses. Edipo ciego - ciego a causa de su conocimiento- es un hombre en un sentido mucho más profundo que el que pudiera tener este concepto cuando aún ignoraba. Por eso puede decir:

A pesar de tantas pruebas, mi avanzada edad y la grandeza de mi alma me hacen juzgar que todo está bien ${ }^{27}$.

El que se arriesga a conocer - a conocerse a sí mismo- se arriesga a la locura, a la ceguera, a la muerte. La mirada del sabio resulta ser, paradójicamente, la de unas cuencas vacías, y no puede eludirse, pues es un destino. La ceguera gana, así, un carácter ambivalente en el pensamiento de Sábato: signo distintivo de los miembros de la secta, a través de la cual el Príncipe de las Tinieblas gobierna el mundo, es, también, rasgo característico del que conoce esa cara oscura de la verdad que es el mal. Fernando Vidal Olmos aducía necesidades estratégicas para justificar la adopción de medidas que tendían a emparentarlo con los ciegos, sus adversarios:

${ }_{25}$ Jaspers, K., Nietzsche. Einfiihrung in das. Verständnis seines Philosophierens (Berlín: De Gruyter, 1950), pp. 227-234.

26 Nietzsche, F., «Die Geburt der Tragödie», en Werke, vol. I, pp. 56-57.

27 El texto de Sófocles es citado por Camus en «Le mythe de Sysiphe», en Essais (París: Gallimard, 1965), p. 197. 
Siempre pensé que no se puede luchar durante años contra un poderoso enemigo sin terminar por parecerse a él; ya que si el enemigo inventa la ametralladora, tarde o temprano, si no queremos desaparecer, también hay que inventarla y utilizarla, y lo que vale para un hecho burdo y físico como un arma de guerra, vale, y con más profundos y sutiles motivos, para las armas psicológicas y espirituales ${ }^{28}$.

Pero la razón de este parentesco es, como Sábato demuestra, más sutil y más temible: dado que la indagación de Fernando $-\mathrm{y}$ del propio Sábato- tiene por objetivo el propio inframundo, la ceguera de los ciegos no puede ser otra que la nuestra. Sólo esto puede explicar que, una vez cegado, Sábato pueda pensar, como el Edipo de Sófocles y el de Camus, que todo está bien. Pero que nadie piense que éste es un juicio moral; al menos no lo es en sentido tradicional. Lo que el «héroe al revés» ha descubierto es, precisamente, la presencia del mal en sí mismo -y en cada uno de nosotros-; lo que, hasta el final de su pesquisa, había sido inconfesable porque, en muchos casos, era irreconocible, porque no existía la determinación de conocerlo. La frase «todo está bien» tendría aquí un sentido más o menos científico: «así es la realidad» o "así son las cosas». Pero, en la medida en que esta exactitud hace referencia al conocimiento de lo que Sábato llama Uno-mismo, recobra el nunca perdido carácter moral. Más aún: tal declaración lleva la moral a una dimensión superior, más exigente que la tradicional, pues hace del reconocimiento de la ubicuidad del mal en nosotros su fundamento.

Hay que sacar a la luz lo oculto, lo subterráneo. Para ello hace falta una mirada que comprenda en sí la ceguera; una mirada que sepa ver en la superficie y en la profundidad, en el mundo de la luz y en el de la ceguera, en la tierra y en el infierno. Sábato ha sabido recoger el críptico mensaje de esa protosabiduría que son los mitos, descifrar, de forma enteramente nueva, la ejemplar historia de Perséfone, hija de Deméter, secuestrada por Hades, Señor de los Infiernos - el Príncipe de las Tinieblas-, para hacerla su compañera. Dicen los historiadores de las religiones, sin duda con toda razón, que para los helenos, que crearon el mito, representaba éste el ciclo de las cosechas: como es sabido, la madre de la secuestrada forzó a Zeus a mediar en un pacto, según el cual Perséfone pasaría la mitad del año con su raptor y la otra mitad en el mundo de la luz, y este movimiento periódico simbolizaría el de la fecundidad de la tierra de labor. Pero lo sagrado no lo es en vano, como no lo es

28 P. 340. 
lo humano: tiene una vida propia, insospechada, latente, que sólo espera el hálito respetuoso y estremecido del hombre mismo para desplegarse. Así ocurre con la mítica figura de Perséfone: lo que más debía inquietar de ella son... sus ojos; esos ojos que han visto ambos mundos. Hacía falta estar dotado de unos ojos para lo sagrado - para lo humano- para sentir inquietud por el misterio de los ojos de Perséfone. Y para comprobar, finalmente, que esa mirada se poseía ya, desde el principio, y que sin ella la indagación no habría sido posible. El camino seguido por el investigador ha sido, sobre todo, el de un traer a la conciencia aquello que ya existía, el de hacer la luz en la tiniebla para, en seguida, aceptar la presencia constante e ineludible de lo tenebroso en nosotros mismos. No puede extrañar que, en la consumación de su obra de ficción - de su obra filosófica- Ernesto Sábato se vea a sí mismo como «una rata con alas», como un repugnante murciélago surgido de sórdidos abismos ${ }^{29}$. Dice mucho en su favor que no vea de igual modo a los demás, y creo que esto no es una simple pose. Su actitud recuerda, por el contrario, a la del Tarrou de La peste. ¿Recuerdan? «Todos estamos más o menos apestados; lo importante es... al menos no contagiar.» Solamente quien ha reconocido en sí la ceguera, la condición de quiróptero, la presencia de la peste, está en condiciones de no contagiar, de no hacer daño. De nuevo encontramos cómo la verdad que pasa por el reconocimiento y la asunción de lo perverso está íntimamente relacionada con esa moral superior. Mirar al mundo y a sí mismo con los ojos de Perséfone es doloroso, trágico; conduce - al menos en primer término- a la escisión del yo y a la separación de lo habitual, de lo cotidiano, de lo establecido. Pero, a consecuencia de esto mismo, faculta — si es que no obliga- al individuo para ejercer su señorío sobre la ajena y, sobre todo, la propia realidad. En la obra de Sábato, el Welfare State ha sido sustituido por el reino del dolor.

Pero no podía ser de otro modo, pues éste es el reino de la verdad.

29 Abaddón el exterminador, p. 448. 
